Bangladesh J. Sci. Res. 28(1): 35-41, 2015 (June)

\title{
INVESTIGATION OF WATER QUALITY FROM THE BRAHMAPUTRA RIVER IN SHERPUR DISTRICT
}

\author{
M.S. Islam*, T. Datta, I.J. Ema, M.H. Kabir and N.T. Meghla \\ Department of Environmental Science and Resource Management, \\ Mawlana Bhashani Science and Technology University, Tangail-1902, Bangladesh
}

\begin{abstract}
The study was conducted to determine the status of physico-chemical parameters of the Brahmaputra river water in Sherpur district and also to assess the monthly variation of the river water. To perform the study the samples were collected from five different stations during the period of December 2013 to May 2014. Various water quality parameters such as transparency, temperature, electrical conductivity (EC), total dissolved solids (TDS), $\mathrm{pH}$, dissolved oxygen (DO), biochemical oxygen demand (BOD), hardness and alkalinity were examined. The study revealed that a slightly variation in water quality at different stations of the river. The mean value of transparency $(42.21 \mathrm{~cm})$, temperature $\left(23.38^{\circ} \mathrm{C}\right)$, EC (351.12 $\mu \mathrm{s} / \mathrm{cm})$, TDS (178.54 mg/l), pH (7.75), DO (4.47 mg/l), BOD (1.02 mg/l), hardness $(82.36 \mathrm{mg} / \mathrm{l})$ and alkalinity $(98.63 \mathrm{mg} / \mathrm{l})$ showed that the present status of the Brahmaputra river water is suitable for all aquatic lives, domestic and agricultural uses. Although the overall status of the river water quality is suitable, degradation was detected in few points which might be due to anthropogenic activities, especially the direct discharge of domestic effluents into river. Thus, necessary initiatives should be taken against such anthropogenic activities to maintain the overall water quality of the Brahmaputra river for its sustainable use.
\end{abstract}

Key words: Brahmaputra river, Water Quality, aquatic lives

\section{Introduction}

Bangladesh is gifted with abundance of rain and river water, but a grave situation exists in terms of availability of pure and sufficient water for drinking, household purpose, agriculture and fisheries. Control of the trans-boundary rivers by upstream countries is the main reason for this situation. Water is one of the vital components of the physical environment (UNCED 1992). In fact, after human resources water is the most abundant resources in Bangladesh the third largest sources of fresh water to discharge to the oceans (Ali 1999). Water, the most important natural resource in the world, has the unique property of dissolving and carrying in suspension a huge variety of chemicals and hence water can easily become contaminated. About one third of the drinking water requirement of the world is obtained from surface sources like rivers, dams, lakes and canals (Jonnalagada and Mhere 2001). Water pollutions caused by the use of pesticides and fertilizer in agriculture and the untreated effluents coming from the industries are poisoning the rivers everywhere (Haque 2008). The surface water pollution issue is considered as one of the most serious problems in most developing countries.

*Corresponding author: <islammstazu@yahoo.com>. 
Most of the rivers in the urban areas of the developing world are the end points of effluents discharged from the industries (Suthar et al. 2010). In most water bodies, various chemical parameters occur in low concentrations. This concentration level increases due to human activities and lack of environmental regulation (Ehiagbonare and Ogunrinde 2010). The water quality concerns not only human on living matter but also other ecosystem. A water quality index expressed as single number is developed to describe overall water quality conditions. Therefore, it is necessary for monitoring the water quality of river by analysis of various physiochemical parameters (BCAS 2000). Brahmaputra river is one of the largest rivers in the world with its basin covering areas in Tibet, China, India and Bangladesh. Its major distributary is the Jamuna river from its right bank. It carries almost $80 \%$ of its water during monsoon (Haque 2008). Due to over uses of fertilizers and pesticides in the surrounding cultivable lands that washed out through surface runoff, which degrade the quality of the Brahmaputra river. In the study, the water quality parameters were investigated from the Brahmaputra river and compared with relevant standard levels to know the present status of the water quality of the river. Keeping all this views in mind an experiment was set up to find out the present status of water quality of the Brahmaputra river and its impacts present condition of the river and to make some recommendations to make it environmentally sustainable on daily life of the surroundings.

\section{Materials and Methods}

The Brahmaputra river is located at the Sherpur district and the total length of the river from its source in southwestern Tibet to the mouth in the Bay of Bengal is about $2850 \mathrm{~km}$ (including Padma and Meghna up to the mouth). Inside the Bangladesh, the Brahmaputra river meets with other important tributaries e.g., the Gadadhar (Sankosh), the Dudkumar, the Dharla and Tista rivers on its right bank in the Kurigram district. Its major distributary is the Jamuna river, from its right bank (Haque 2008).

The study was conducted for a period of 6 months from December 2013 to May 2014 at the Brahmaputra river. Samples were collected from five different sampling stations, such as St-1, St2, St-3, St-4 and St-5, of the Brahmaputra river. The location of the sampling stations is given in Table 1. From each sampling station, $500 \mathrm{ml}$ of water were collected by plastic bottles. Water samples were collected from all stations at one month interval in the study area. Before sampling, the bottles were cleaned and washed with detergent solution and rinsed 3 to 4 times with the water to be sampled. Hydrochloric acid was used as preservative in these bottles and containing samples were sealed immediately to avoid exposure to air and placed into the safe place. The bottles were screwed carefully and marked with the respective identification number.

The water quality parameters such as $\mathrm{pH}$, temperature, transparency, DO, EC and TDS were measured by pH meter (model-pH Scan WP 1, 2, Malaysia), thermometer (Celsius scale), Secchi disk, DO meter, EC meter (model-HM digital, Germany) and TDS meter, respectively. Alkalinity was measured by titration method with $0.1 \mathrm{~N} \mathrm{HCl}$ after adding 2 - 3 drops of methyl-orange indicator. The EDTA method was used to determine the hardness of water where Eriochrome 
Black T was used as indicator and titration with EDTA solution. The Biological Oxygen Demand (BOD) was measured by two steps where initial BOD $\left(\mathrm{BOD}_{1}\right)$ was measured immediately after collection and after 5 days $\mathrm{BOD}\left(\mathrm{BOD}_{5}\right)$ was measured by incubation in the dark condition at $20^{\circ} \mathrm{C}$ for 5 days. Then the total BOD $\left(\mathrm{BOD}_{1}-\mathrm{BOD}_{5}\right)$ was measured according to Trivedy and Goel (1984), and Huq and Alam (2005).

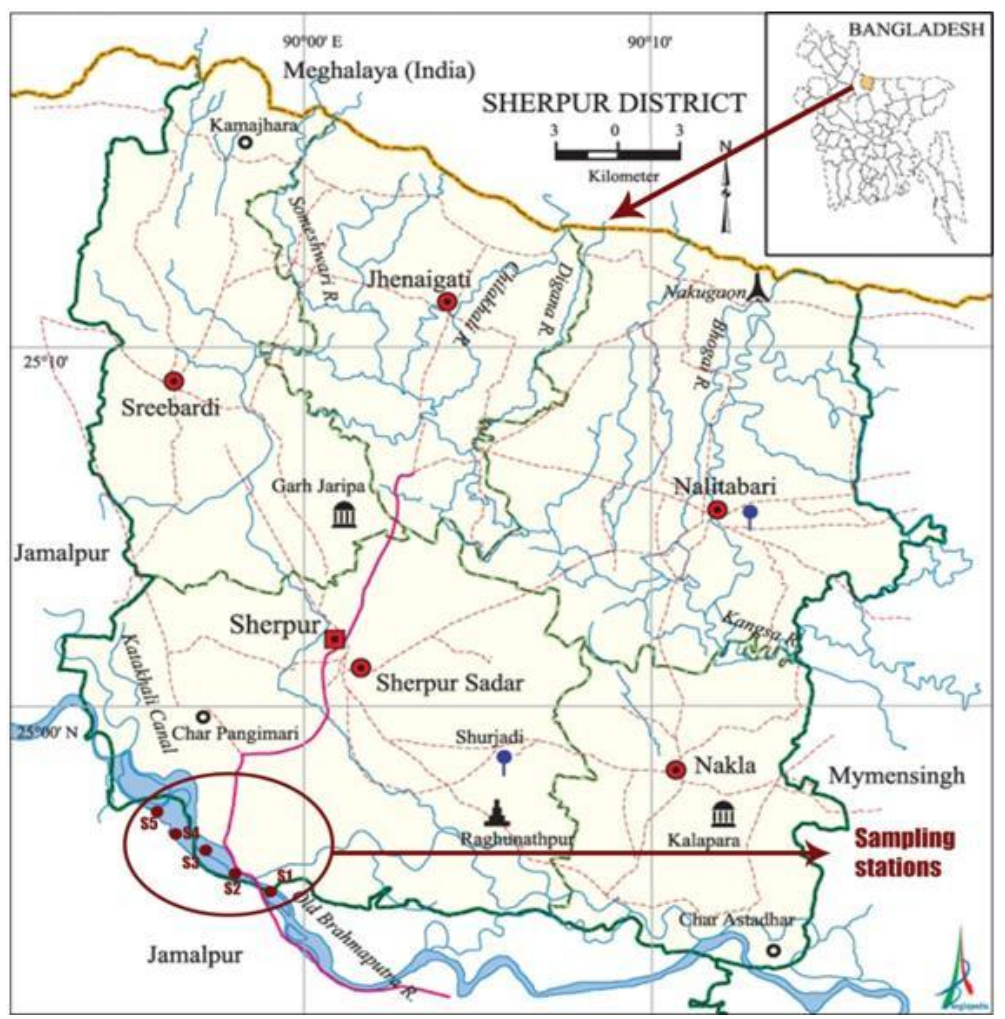

Fig. 1. Map showing the sampling stations in the Brahmaputra river (Banglapedia 2012).

Table 1. Location of the water sampling stations of the Brahmaputra river.

\begin{tabular}{llcc}
\hline Sl No. & Sampling points & Label & Distance from each others \\
\hline Station 1 & Sherpur Bridge & St-1 & 0 \\
Station 2 & Baniya Bazar & St-2 & 1 km from St-1 \\
Station 3 & Sokal Bazar & St-3 & $2 ~ "$ \\
Station 4 & Bokul Tola & St-4 & 3 " \\
Station 5 & Balughata & St-5 & 4 " \\
\hline
\end{tabular}

The collected data were compiled and tabulated in proper form. The Microsoft Office Excel software was used to present and interpret the collected data. 


\section{Results and Discussions}

It is revealed from the study that the lowest transparency was $41.44 \mathrm{~cm}$ at the St-4 and highest transparency was $42.77 \mathrm{~cm}$ at the St-2. In the month of December, January and May transparency was not analyzed due to insufficient laboratory facilities. Hossain et al. (2012) stated that the transparency of the productive fresh water ranged from $35-45 \mathrm{~cm}$. The result indicated that the transparency of the river water was within the standard limit and suitable for aquatic environment. Temperature recorded in the river water reflects that it changed with time and seasons. The study showed that the lowest temperature was at the St $5\left(21.88^{\circ} \mathrm{C}\right)$ and highest temperature was at the St-2 $\left(23.84^{\circ} \mathrm{C}\right)$. The maximum temperature was found in the month of May (Pre-monsoon) and

Table 2. Variations of different physical parameters of five stations in the Brahmaputra river.

\begin{tabular}{|c|c|c|c|c|c|c|c|c|}
\hline \multirow[t]{2}{*}{ Parameter } & \multirow[t]{2}{*}{ Stations } & \multicolumn{6}{|c|}{ Months } & \multirow[t]{2}{*}{ Mean \pm SD } \\
\hline & & Dec. & Jan. & Feb. & Mar. & Apr. & May & \\
\hline \multirow[t]{6}{*}{ Transparency $(\mathrm{cm})$} & St-1 & N/A & N/A & 39.50 & 44.00 & 44.33 & N/A & $42.61 \pm 2.69$ \\
\hline & St-2 & N/A & N/A & 39.50 & 43.50 & 45.33 & N/A & $42.77 \pm 2.98$ \\
\hline & St-3 & N/A & N/A & 36.83 & 44.83 & 45.33 & N/A & $42.33 \pm 4.76$ \\
\hline & St-4 & N/A & N/A & 36.33 & 43.33 & 44.66 & N/A & $41.44 \pm 4.47$ \\
\hline & St-5 & N/A & N/A & 37.00 & 44.33 & 44.50 & N/A & $41.94 \pm 4.28$ \\
\hline & Avg. & N/A & N/A & 37.83 & 43.99 & 44.83 & N/A & $42.21 \pm 3.84$ \\
\hline \multirow[t]{6}{*}{ Temperature $\left({ }^{\circ} \mathrm{C}\right)$} & St-1 & 18.50 & 18.63 & 21.56 & 25.70 & 28.73 & 29.30 & $23.73 \pm 4.85$ \\
\hline & St-2 & 18.46 & 18.90 & 21.60 & 25.66 & 29.06 & 29.36 & $23.84 \pm 4.88$ \\
\hline & St-3 & 18.30 & 18.73 & 21.56 & 25.63 & 28.66 & 29.36 & $23.70 \pm 4.87$ \\
\hline & St-4 & 18.46 & 18.50 & 21.73 & 25.86 & 28.66 & 29.43 & $23.77 \pm 4.90$ \\
\hline & St-5 & 18.46 & 18.53 & 21.63 & 25.63 & 28.60 & 29.33 & $21.88 \pm 4.33$ \\
\hline & Avg. & 18.44 & 18.66 & 21.67 & 25.69 & 28.74 & 29.36 & $23.38 \pm 4.77$ \\
\hline \multirow[t]{6}{*}{$\mathrm{EC}(\mu \mathrm{S} / \mathrm{cm})$} & St-1 & 364.00 & 363.30 & 352.60 & 325.30 & 386.60 & 357.60 & $358.20 \pm 19.90$ \\
\hline & St-2 & 353.30 & 357.00 & 352.30 & 319.00 & 385.60 & 330.60 & $349.60 \pm 23.11$ \\
\hline & St-3 & 350.33 & 354.30 & 355.60 & 317.30 & 384.60 & 326.60 & $348.10 \pm 23.84$ \\
\hline & St-4 & 353.00 & 347.60 & 354.30 & 318.60 & 383.00 & 348.00 & $350.70 \pm 20.51$ \\
\hline & St-5 & 353.30 & 354.30 & 353.00 & 318.30 & 386.30 & 329.00 & $349.00 \pm 23.65$ \\
\hline & Avg. & 354.79 & 355.30 & 353.56 & 319.70 & 385.22 & 338.36 & $351.12 \pm 22.20$ \\
\hline \multirow[t]{6}{*}{ TDS (mg/l) } & St-1 & 185.30 & 184.60 & 179.00 & 159.00 & 197.00 & 176.60 & $180.20 \pm 12.58$ \\
\hline & St-2 & 185.00 & 186.00 & 176.30 & 159.60 & 196.30 & 167.30 & $178.40 \pm 13.42$ \\
\hline & St-3 & 184.60 & 183.60 & 176.60 & 157.00 & 198.00 & 164.30 & $177.30 \pm 14.85$ \\
\hline & St-4 & 185.30 & 184.00 & 175.60 & 157.00 & 197.30 & 173.00 & $178.70 \pm 13.65$ \\
\hline & St-5 & 185.33 & 183.60 & 177.30 & 159.30 & 197.30 & 165.60 & $178.10 \pm 13.86$ \\
\hline & Avg. & 185.11 & 184.36 & 176.96 & 158.38 & 197.18 & 169.36 & $178.54 \pm 13.67$ \\
\hline
\end{tabular}

N/A = Not Analyzed. Avg. = Average and \pm SD = Standard deviation.

minimum temperature was found in the month of December (Post-monsoon). In case of river water temperature, the DoE standard for sustaining aquatic life is within 20 to $30^{\circ} \mathrm{C}$ both in dry and wet season (Bhaumik et al. 2006). In the month of December and January temperature was below the DoE standard limit. All of the samples of river water were within the DoE standard during February, March, April and May (Table 2). 
The electrical conductivity (EC) of five sampling stations was ranged from 325.3 to 386.6, 319 to $385.6,317.3$ to 384.6 , 318.6 to 383 and 318.3 to $386.3 \mu \mathrm{S} / \mathrm{cm}$, respectively. Due to seasonal variations, all stations showed lower EC value than the standard of $700 \mu \mathrm{S} / \mathrm{cm}$ (EQS 1997). Total Dissolved Solids (TDS) is an important physical parameter in water, mainly indicates the presence of various kinds of materials in water (Rahman et al. 2012). The mean values of total dissolved solids (TDS) of the five sampling stations were found to vary from 159 to 185.3, 159.6 to 196.3, 157 to 198,157 to 197.3 and 159.3 to $197.3 \mathrm{mg} / \mathrm{l}$, respectively. The maximum TDS was found in the month of April (Pre-monsoon) and minimum TDS was found in the month of March (Postmonsoon). The TDS ranges both in post and pre-monsoon seasons were exceeded the standard

Table 3. Variations in different chemical parameters of five stations in the Brahmaputra river.

\begin{tabular}{|c|c|c|c|c|c|c|c|c|}
\hline \multirow[t]{2}{*}{ Parameter } & \multirow[t]{2}{*}{ Stations } & \multicolumn{6}{|c|}{ Months } & \multirow[t]{2}{*}{ Mean \pm SD } \\
\hline & & Dec. & Jan. & Feb. & Mar. & Apr. & May & \\
\hline \multirow[t]{6}{*}{$\mathrm{pH}$} & St-1 & 7.49 & 7.53 & 7.53 & 8.41 & 8.09 & 7.21 & $7.71 \pm 0.44$ \\
\hline & St-2 & 7.53 & 7.43 & 7.56 & 8.45 & 8.18 & 7.32 & $7.74 \pm 0.45$ \\
\hline & St-3 & 7.48 & 7.46 & 7.49 & 8.28 & 8.50 & 7.54 & $7.79 \pm 0.46$ \\
\hline & St-4 & 7.48 & 7.42 & 7.48 & 8.44 & 8.45 & 7.33 & $7.76 \pm 0.52$ \\
\hline & St-5 & 7.57 & 7.49 & 7.60 & 8.13 & 8.18 & 7.52 & $7.74 \pm 0.31$ \\
\hline & Avg. & 7.51 & 7.47 & 7.53 & 8.34 & 8.30 & 7.38 & $7.75 \pm 0.44$ \\
\hline \multirow[t]{6}{*}{ DO (mg/l) } & St-1 & 5.56 & 5.26 & 5.36 & 3.46 & 4.60 & 2.86 & $4.51 \pm 1.11$ \\
\hline & St-2 & 5.33 & 5.53 & 5.00 & 3.40 & 4.40 & 2.70 & $4.39 \pm 1.13$ \\
\hline & St-3 & 5.66 & 5.40 & 4.76 & 3.30 & 4.43 & 2.76 & $4.38 \pm 1.15$ \\
\hline & St-4 & 5.73 & 5.56 & 5.10 & 3.53 & 4.33 & 2.53 & $4.46 \pm 1.25$ \\
\hline & St-5 & 5.70 & 5.76 & 5.46 & 3.40 & 4.50 & 2.73 & $4.59 \pm 1.28$ \\
\hline & Avg. & 5.51 & 5.50 & 5.14 & 3.42 & 4.45 & 2.72 & $4.47 \pm 1.18$ \\
\hline \multirow[t]{6}{*}{ Hardness (mg/l) } & St-1 & 1.36 & 0.56 & 0.30 & 0.66 & 1.43 & 0.43 & $0.79 \pm 0.48$ \\
\hline & St-2 & 1.80 & 1.53 & 0.86 & 0.43 & 1.40 & 0.53 & $1.09 \pm 0.56$ \\
\hline & St-3 & 1.53 & 1.53 & 0.73 & 0.46 & 1.46 & 0.43 & $1.02 \pm 0.54$ \\
\hline & St-4 & 1.53 & 1.70 & 0.50 & 0.53 & 1.53 & 0.40 & $1.03 \pm 0.61$ \\
\hline & St-5 & 1.76 & 1.53 & 1.23 & 0.73 & 1.53 & 0.26 & $1.17 \pm 0.57$ \\
\hline & Avg. & 1.60 & 1.37 & 0.72 & 0.56 & 1.47 & 0.41 & $1.02 \pm 0.55$ \\
\hline \multirow[t]{6}{*}{ Alkalinity (mg/l) } & St-1 & 98.00 & 105.00 & 75.00 & 130.00 & 75.00 & 83.33 & $94.38 \pm 21.29$ \\
\hline & St-2 & 97.66 & 105.00 & 100.00 & 111.66 & 100.00 & 92.66 & $101.16 \pm 6.51$ \\
\hline & St-3 & 84.33 & 105.00 & 125.00 & 115.00 & 125.00 & 87.66 & $106.99 \pm 17.91$ \\
\hline & St-4 & 91.00 & 106.50 & 92.66 & 103.33 & 91.66 & 87.33 & $95.41 \pm 7.64$ \\
\hline & St-5 & 104.00 & 110.00 & 84.00 & 95.00 & 86.66 & 91.66 & $95.22 \pm 10.07$ \\
\hline & Avg. & 95.10 & 106.30 & 95.33 & 110.10 & 95.66 & 88.53 & $98.63 \pm 12.68$ \\
\hline
\end{tabular}

limit of 165 ppm (Table 2). It could be due to cut off the river bank for agriculture practices, cultivation in the river bed and along the bank area as well as use of fertilizers and pesticides, and river bank erosion (Huq and Alam 2005). A positive relation was found between EC and TDS where the EC value increased with increasing the TDS concentration. 
The study revealed that the water was rather alkaline. The study found minimum $\mathrm{pH}$ value at the St-1 (7.71) and highest $\mathrm{pH}$ value at the St-3 (7.79). The standard limit of $\mathrm{pH}$ for inland surface water is 6.5 to 8.5 (EQS 1997). It may be inferred from the study that $\mathrm{pH}$ of all the sampling stations was within the acceptable range.

Adequate DO is necessary for good water quality, survival of aquatic organism and decomposition of waste by microorganism (Islam et al. 2010). The study found to lowest DO concentration at the St-3 $(4.38 \mathrm{mg} / \mathrm{l})$ and highest concentration of DO at the St-5 $(4.59 \mathrm{mg} / \mathrm{l})$. In the study the maximum DO was found in the month of January (Post-monsoon) and minimum DO was found in the month of May (Pre-monsoon) (Table 3) and this lower level was observed due to agricultural slurry, surface runoff of nutrients and enrichment by nutrients (Rahman et al. 2012). The study found to be lowest BOD concentration at the St-1 $(0.79 \mathrm{mg} / \mathrm{l})$ and highest BOD concentration at the St-5 $(1.17 \mathrm{mg} / \mathrm{l})$. Lower BOD concentration was found in all the six months in the Brahmaputra river (Table 3) which was suitable for fisheries production, recreation and irrigation.

According to Swingle (1967), a total hardness of $15 \mathrm{ppm}$ or more is suitable for fish culture. The study found the lowest hardness content was $68.38 \mathrm{mg} / \mathrm{l}$ at the St- 4 and highest $96.05 \mathrm{mg} / \mathrm{l}$ at the St-1 (Table 3). All six months showed that the Brahmaputra river water was suitable for fish culture because hardness of all sampling stations were within the standard limit $123 \mathrm{mg} / \mathrm{l}$ as set by Huq and Alam (2005). The study found the lowest alkalinity content was $94.38 \mathrm{mg} / \mathrm{l}$ at the St-1 and highest was $106.99 \mathrm{mg} / \mathrm{l}$ at the St-3. The ranges of alkalinity were found to vary from 84-110 and 75 - $130 \mathrm{mg} / \mathrm{l}$ in post-monsoon (Dec-Jan) and pre-monsoon (February - May) season. Premonsoon season showed more alkaline water than post-monsoon season. The river banks were widely used for agricultural practices and during pre-monsoon most of the crops are harvested; these might be cause of the result.

\section{Conclusion}

The result of the study concluded that the present status of the Brahmaputra river water is suitable for all aquatic lives, domestic and agricultural uses. However, the water quality of the river is being altered in a few areas as a result of domestic effluents direct discharge into river and of others human activities along the banks of the river. Necessary initiatives, therefore, should be taken against river bank erosion, use of excessive fertilizers and pesticides to improve the overall quality of the water of Brahmaputra river for sustainable management. Moreover, further research

and periodic monitoring of river water quality is of importance for the improvement or maintenance of the water of Brahmaputra river.

\section{References}

Ali, H. A. 1999. Pollution assessment of surface and ground water in northern and eastern piedmont plains. M. S. Thesis, Department of Environmental Science, Bangladesh Agricultural University, Mymensingh. Banglapedia. 2012. National Encyclopedia of Bangladesh. 
BCAS (Bangladesh Center for Advanced Studies). 2000. Pollution study and management of aquatic ecosystem through community husbandry (MACH). Dhaka, Bangladesh.

Bhaumik, U., P. Das and T. Paria. 2006. Impact of plankton structure on primary production in two beels of West India. Bangladesh Journal of Fisheries Research 10(1): 01-11.

Ehiagbonare, J.E. and Y.O. Ogunrinde. 2010. Physico-chemical analysis of fish pond water in Okada and its environs, Nigeria. African Journal of Biotechnology 9(36): 522-528.

EQS (Environmental Quality Standard). 1997. Bangladesh Gazette, Registered. Department of Environment, Ministry of Environment and Forest, Government of Bangladesh.

Haque, M. I. 2008. Water resources management in Bangladesh. Anushilan, Chuadanga and Dhaka. pp. 1, 20 and 67.

Hossain, A. M. I., S. K. Adhikary and M. M. A. Elahi. 2012. Assessment of shallow ground water quality from six ward of Khulna city corporation, Bangladesh. International Journal of Applied Sciences and Engineering Research 1(3): 488-498.

Huq, S. M. I. and M. D. Alam. 2005. A Handbook on analysis of soil, plant and water. BACER-DU, University of Dhaka. Bangladesh.

Islam, M. S., Suravi and N. T. Meghla. 2010. Investigation on water quality in Ashulia beel, Dhaka. Bangladesh Journal of Fisheries Resources 14(1-2): 55- 64.

Jonnalagada, S. B. and G. Mhere. 2001. Water quality of the river in the eastern highlands of Zimbabwe. pp. 35.

Rahman, A. K. M. L., M. Islam, M. Z. Hossain and M. A. Ahsan. 2012. Study of the seasonal variations in Turag river water quality parameters. African Journal of Pure and Applied Chemistry 6(10): 144-148.

Suthar, S., J. Sharma, M. Chabukdhara and A. K. Nema. 2010. Water quality assessment of river Hindon at Ghaziabad, India: impact of industrial and urban wastewater. Environmental Monitoring and Assessment 165: $103-112$

Swingle, H. S. 1967. Standardization of chemical analysis for waters and pond muds. FAO Fish. Rep. 4(44): 397-421.

Trivedy, R. K. and P. K. Goel. 1984. Chemical and biological methods for water pollution studies. Environmental publications, KARAD. pp. 42-74.

UNCED (The United Nations Conference on Environment and Development). 1992. Protection of the quality and supply of freshwater resources: Application of integrated approaches to the development, management and use of water resources. Chapter 18, Agenda 21.

(Manuscript received on 8 April, 2015; revised on 3 August, 2015) 